\title{
INTEGRATING MULTISOURCE OF BATHYMETRY DATA FOR UPDATING BASEPOINT AND BASELINE POSITIONS OF MARITIME BOUNDARY
}

\author{
Ratna Sari DEWI ${ }^{\text {* (D), Tia Rizka Nuzula RACHMA } 1 \text { (D) Ibnu SOFIAN }}{ }^{1}$ (D),

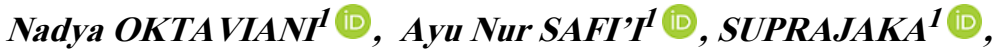 \\ Astrit RIMA YANTI' and Eko ARTANTO ${ }^{1}$
}

DOI: $10.21163 /$ GT_2022.171.02

\begin{abstract}
:
The research presents an alternative method to update the position of basepoints and baselines of maritime boundary especially for the area with lack of bathymetry data. We used multisource bathymetry data for instance the national bathymetry, the national digital elevation model, and echosounding measurement data. We then integrated them with satellite derived bathymetry to provide a dense depth point in shallow water. In this case, data limitation due to the difficulty in reaching for example the outermost location was overcome by using remote sensing technology. The spline interpolation-based method was successful to integrate those multisource data and obtained quite detail information and less noisy bathymetry data. Furthermore, the LAT and HAT coastlines were able to update the positions of basepoint and baseline in the study area. We developed a new maritime boundary consisting of a normal baseline and straight lines across the mouth of three rivers and integrate them with the existing archipelagic baselines. The results can be used as a basis knowledge to support negotiations in delimiting maritime boundaries so that a proportionate and equitable agreement with neighboring countries can be achieved.
\end{abstract}

Key-words: Basepoints; Baselines; Coastlines; SDB; Gridding method; Maritime boundary.

\section{INTRODUCTION}

Indonesia shares land and sea borders with other countries. Its maritime boundaries are divided into several maritime areas, including territorial sea, contiguous zone, the Exclusive Economic Zone, and continental shelf. To determine boundaries in these areas, defining basepoints and baselines is crucial since the baseline is the measurement reference for the boundary lines (Arsana, Rizos and Schofield, 2006). These basepoints and baselines are determined by Indonesia via Government Regulation ref. no. 38 of 2002 and Government Regulation ref. no. 37 of 2008 (Indonesian Government., 2002, 2008). Based on these regulations, archipelagic baselines are obtained from basepoints that are located in the low water line, namely the average position of the low water line (Indonesian Government., 2002). Based on NOAA (NOAA, 2021), the mean low water line (MLLW) is obtained from the average measurement of the lowest water level observed every day during the tidal datum period, which is 19 years. Nevertheless, with the current development of survey and mapping methodologies, there are various new methods that can be used to determine the position of these basepoints, especially when the availability of historical tide measurements is limited. Moreover, there is no internationally recognized standard method for determining the position of this archipelagic baselines (Specht, Specht, Waz, Dabrowski, et al., 2019). However, the minimum quality of these measurements can be referred to in the IHO guidelines (IHO., 2008).

In the literature, measurement of basepoints and baselines can be carried out using various methods, including the tachymetric method (Specht et al., 2017), through the LIDAR system

\footnotetext{
${ }^{1}$ Geospatial Information Agency, JI. Raya Jakarta - Bogor KM.46, Cibinong, 16911, Indonesia,

*Corresponding author: dewi.rsd@gmail.com; tia.rizka@big.go.id; ibnu.sofian@big.go.id; nadya.oktaviani@big.go.id; ayu.nur@big.go.id; suprajaka@big.go.id; astrit.rimayanti@big.go.id; eko.artanto@big.go.id.
} 
(Sinclair, Stephenson and Barker, 2003), using UAVs (Specht, Specht, Waz, Dabrowski, et al., 2019), and very high resolution imagery.

The use of UAVs and satellite imagery is primarily intended for very shallow waters, where ships cannot use echosounders because of the very shallow depths (Specht, Specht, Waz, Naus, et al., 2019). Furthermore, it is stated that although the tachymetric method is the most accurate method, it is less effective because large coverage requires considerable time and cost (Specht, Specht, Waz, Dabrowski, et al., 2019). Therefore, the use of remote sensing data has recently been increasingly developing in providing an alternative for mapping basepoints and baselines. This method will help the updating process since the position of these basepoints and baselines may be dynamic (Specht, Specht, Waz, Naus, et al., 2019).

At present time, baselines at the study area has been developed by only connecting two basepoints due to limited data available in this location. Coastline surveys based on datums have never been carried out and bathymetric data around the site is also very minimal. Due to limited data availability to develop an accurate coastline position, the related baseline intersects part of the mainland as in Fig. 1. This study aims to develop an alternative method in determining an accurate position of basepoints and baselines of the Indonesian archipelago. We expect this method can be used as an alternative in determining the position of basepoints to complement Indonesia's maritime border data. The location of basepoints and baselines refers to the position of coastlines based on the lowest tidal datum (Lowest Astronomical Tide/LAT) and the highest tidal datum (Highest Astronomical Tide/HAT). This is in accordance with the Information Geospatial Law of Indonesia which mandates that Indonesia coastlines are categorized into three types of datum level: LAT, MSL and HAT (Geospatial Information Agency., 2011). Moreover, in 1997, to the member of IHO, Tidal Committee suggested the use of LAT as the reference for the chart datum. The LAT and HAT are calculated over at least 18.6 year period of harmonic constants derived from at least one year observation (FIG Commission 4 and 5., 2006). In addition, because of the difficulty in reaching the outermost location, the use of remote sensing data is expected to be able to overcome the problem of data limitations.

\section{STUDY AREA}

For the case study, a basepoint was selected, namely: TD.161B located in Cape Simansih, Siberut Island, part of Mentawai Islands, Indonesia. TD.161B is located at the coordinates of $01^{\circ} 40^{\prime} 43^{\prime \prime} \mathrm{S}$ and $98{ }^{\circ} 52^{\prime} 35^{\prime \prime}$ E. This basepoint is in the western part of Sumatra, facing the Indian Ocean and not bordering other countries. The closest basepoint to the TD.161B is TD.162 located in Cape Sakaladat, Siberut Island, and TD.161 in Sinyaunyau Island (Fig. 1).

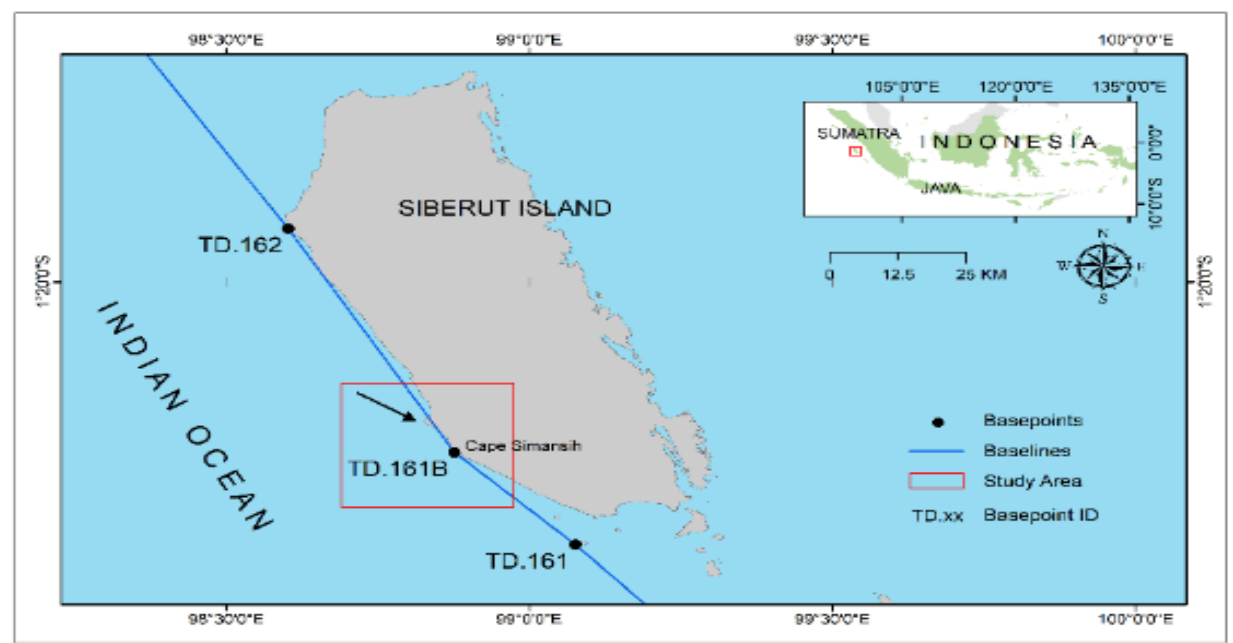

Fig. 1. Location of study area on a map of Indonesia including the location of existing basepoints and baselines. Black arrow shows the position at which the baseline intersects the mainland. 
When checking the baseline carefully, we observed that the baseline intersects the land portion as indicated by black arrow in Fig. 1.

Tidal characteristics in the Mentawai Islands are dominated by semi-diurnal tides (Suparno., 2006) with wave height is ranging from $0.5 \mathrm{~m}$ up to $3 \mathrm{~m}$ depending on seasons (Dewi, Sugianto and Diponegoro, 2018). Siberut Island as the National Park Area is a biosphere reserve of UNESCO since 1981. It has a diversity of natural ecosystem such as coral reefs, seagrass beds and mangroves. On the other hand, Siberut has potential of disasters since this area is the meeting place of ocean and continental plates that is prone to earthquake and tsunami (Mustafa, 2010; Karim, 2011).

\section{DATA AND METHODS}

\subsection{Elevation and bathymetry data}

Bathymetry data from various sources (see Fig. 2) were used in this experiment and described as follows:

a) National Digital Elevation Model (DEMNAS)

The National DEM is developed from multi data sources including IFSAR (5 m resolution), TERRASAR-X (5 m resolution) and ALOS PALSAR (11.25 m resolution) data. Further, the stereo-plotting mass point data is also incorporated in the process. The spatial resolution of DEMNAS is 0.27 -arcsecond. It refers to the EGM2008 vertical datum (Geospatial Information Agency., 2018b).

b) Indonesian National Bathymetry Data (INBD)

National bathymetry is developed from the inversion of gravity anomaly data by using the altimetry data. Furthermore, sounding data from single beam and multibeam measurements are incorporated as well. The spatial resolution of the BATNAS data is 6arc-second and it refers to the MSL datum (Geospatial Information Agency., 2018b). The Geospatial Information Agency already has the National Bathymetry (INBD) data, which combines GEBCO data with several bathymetric measurements in only a few areas (Julzarika et al., 2021).

c) Single Beam Echosounder Data (SBES)

For the study area, the best available data was from single beam echosounder (SBES) measurement provided by the Indonesia Geospatial Information Agency. The SBES survey was conducted in 2019. Since the data has been corrected for zero tidal influences, no additional tidal correction was needed. The depth information ranges from $1 \mathrm{~m}$ up to $29.9 \mathrm{~m}$. Table 1 presents the number of measurement points available within $2 \mathrm{~m}$ depth range. This SBES measurement data was used for two purposes: a) as an input when performing coastline model (gridding bathymetry and topography data); and b) as an input to build and validate the SDB model in extracting bathymetry information.

d) Satellite Derived Bathymetry Data (SDB)

SDB data were derived by performing Random Forest (RF) to Sentinel 2A. Further detail on the processing of the SDB model is available in Section 2.3.1.

Table 1.

Number of measurement points within $\mathbf{2} \mathbf{m}$ depth ranges for hydrographic data.

\begin{tabular}{cccccccccc}
\hline Overall & $>0 \mathrm{~m}$ & $1-3 \mathrm{~m}$ & $3-5 \mathrm{~m}$ & $5-7 \mathrm{~m}$ & $7-9 \mathrm{~m}$ & $9-11 \mathrm{~m}$ & $11-13 \mathrm{~m}$ & $13-15 \mathrm{~m}$ & $>15 \mathrm{~m}$ \\
\hline 97,971 & N/A & 6,645 & 4,593 & 7,119 & 24,770 & 26,465 & 22,576 & 3,847 & 1,956 \\
\hline
\end{tabular}




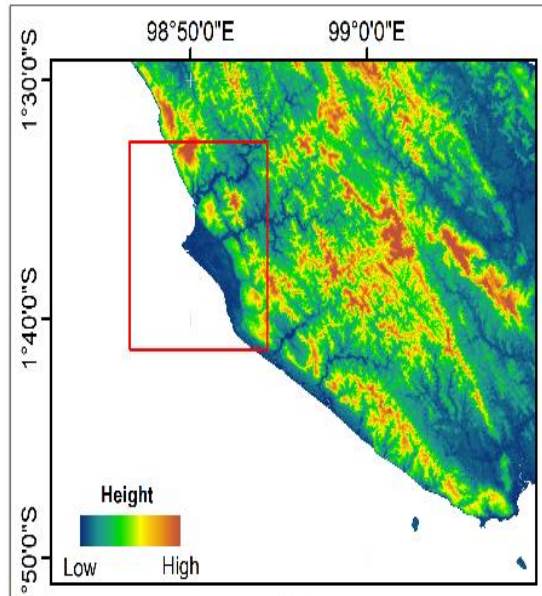

(a)

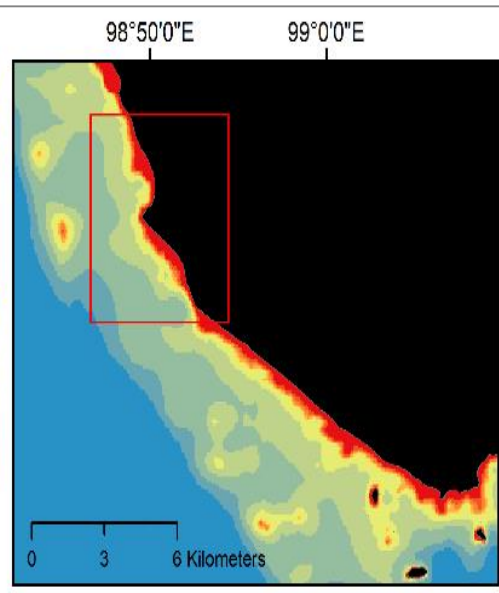

(b)

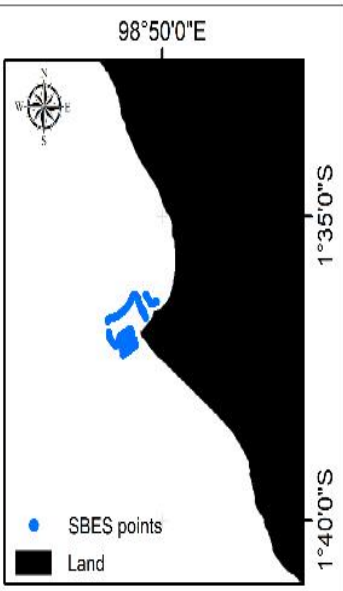

(c)

Fig. 1. The visualization of bathymetry data that were used for coastline model, namely a) composite of the national DEM; b) the Indonesian national bathymetry data; and c) SBES measurement points.

\subsection{Tide gauge data}

Hourly tides data observation was used in this research. The data were obtained from Mailepet tide gauge station in the southern part of Siberut Island located at the coordinates of $01^{\circ} 33^{\prime} 49.7^{\prime \prime} \mathrm{S}$ and $99^{\circ} 11^{\prime} 49.2^{\prime \prime}$ E (Geospatial Information Agency., 2018a). The data which was made available from the Indonesian Geospatial Information Agency (Badan Informasi Geospasial) was recorded from 23 February 2011 up to 1 September 2020. The tide data was used in estimating the LAT and HAT position before performing coastline model.

\subsection{Satellite image}

Four bands of Sentinel 2A were used to extract bathymetry information from remote sensing data (satellite derived bathymetry). The spectral bands were consisting of blue $(0.49 \mu \mathrm{m})$, green $(0.56 \mu \mathrm{m})$, red $(0.665 \mu \mathrm{m})$, and near infrared $(0.842 \mu \mathrm{m})$ parts of the spectrum (ESA, 2015). For the study, we used level 2A format from the ESA website, i.e., Copernicus Open Access (ESA, 2020). The image was recorded on March 25th, 2019 with $10 \mathrm{~m}$ spatial resolution and in bottom of atmosphere reflectance $(\mathrm{BoA})$ format. A standard radiometric and geometric correction has been applied to the image by the provider (ESA, 2015).

\subsection{Other data}

To compare the results of the method proposed in this study, we used topographic map of Siberut Island, the Indonesian archipelagic baseline, boundaries of territorial sea, contiguous zone, and the economic exclusive zone, Indonesian river data, and the existing basepoints of the surrounding area. Those data were obtained from the Geospatial Information Agency of Indonesia.

\subsection{SDB model}

To perform the SDB model, we used $80 \%$ of the SBES measurement data that was randomly selected as the training data. The remaining $20 \%$ of the SBES measurement was used for the testing data. For the next step, we applied Random Forest (RF) to derive depth information. We set the two parameters of RF, mtry and ntree to obtain the best accuracy (Breiman, 2001). The ntree values were set from 50-1,000 trees with intervals of 50. Meanwhile, the mtry values were tested from 110 with intervals of 1 . 
Furthermore, the validation of the SDB model was conducted by using 5-fold cross validation (H2O, 2021). In fact, for this research, we made experiment by assessing not only RF but also support vector machine (SVM), however, RF outperformed SVM. Therefore, in this study, we applied RF for the extraction of bathymetry from satellite images. For the detail information about RF, readers are suggested to check literatures (Manessa et al., 2016; Sagawa et al., 2019).

\subsection{The LAT and HAT estimation for datum-based coastlines}

T-TIDE package in MATLAB was employed to analyzed the tide gauge data (Pawlowicz, Beardsley and Lentz, 2002). Least squares harmonic analysis was applied by this package to identify the components and predictions of tide by using up to 71 tidal components. In this case, the harmonic analysis application is conducted by fitting the chosen harmonic constituents to the sea level observation. The following equation was used to estimate a tidal function by fitting the sea level observation (Bruce B. Parker, 2007; Siddig, Al-subhi and Alsaafani, 2019):

$$
z(t)=z_{0}+\sum_{i=1}^{m} f_{i} z_{i} \cos \left(\omega_{i} t+u_{i}-k_{i}^{*}\right)
$$

where: $\mathrm{t}$ is the time in serial hours, $\mathrm{z}(\mathrm{t})$ is a predicted water level at $\mathrm{t}, \mathrm{z}_{0}$ is the mean water level, $\mathrm{f}_{\mathrm{i}}$ is a lunar node factor for the $\mathrm{i}^{\text {th }}$ constituent, $\mathrm{Z}_{\mathrm{i}}$ is a mean amplitude for the $\mathrm{i}^{\text {th }}$ constituent over 18.6-year lunar node cycle, $\omega_{\mathrm{i}}$ is the frequency of the $\mathrm{i}^{\text {th }}$ constituent, $\mathrm{u}_{\mathrm{i}}$ is the nodal phase for the $\mathrm{i}^{\text {th }}$ constituent, $\mathrm{k}_{\mathrm{i}} *$ is the phase of the $\mathrm{i}^{\text {th }}$ constituent for the period origin is utilized, and $\mathrm{m}$ is a number of constituents.

Nine-year observation data from 23 February 2011 up to 1 September 2020 were used in this study. The least squares method was applied to fit the trend which represents the general patterns of the time series observation over its period (Siddig, Al-subhi and Alsaafani, 2019). The LAT and HAT were calculated over a minimum period of 19 years which was during a full nodal period using the harmonic constant values derived from nine-year observations (FIG Commission 4 and 5., 2006; Thiébot, Guillou and Droniou, 2020). The LAT is defined as the lowest predicted tide level under average meteorological conditions and under any astronomical conditions. Meanwhile, the HAT is refers to the highest level of water that can be predicted under any combinations of astronomical situation (IHO., 2008; PCTMSL, 2014). For more information on the analysis of harmonic method, readers are suggested to check references (Ko et al., 2018; Siddig, Al-subhi and Alsaafani, 2019).

\subsection{Integrating elevation and bathymetry extracting coastlines}

Gridding method was applied to integrate all various sources of data, including land elevation and bathymetry data so that the seamless digital elevation and bathymetry model could be obtained. Hell and Jakobsson (2011) developed the gridding method based on interpolation with spline tension at several resolutions determined by the source of data density. This method is found to be suitable when integrating various kinds of data for instance low-resolution National Bathymetry Data and high-resolution echo sounding measurements (Becker et al., 2009; Hell and Jakobsson, 2011). In this study, a self-developed FORTRAN-based program based on the method proposed by Hell and Jakobsson (2011) was used to compile and develop the DEBM.

Coastline model can be developed in several ways (Boak and Turner, 2005; Dewi et al., 2018), for example by classifying features on the coast using aerial photographs for instance the position of highest water line (Ford, 2013; NOAA, 2021). The coastline can also be built based on tidecoordinated coastline, for example, by referring to the mean high water line whose information is obtained, for example using LIDAR data or field measurements (Liu, 2008; Kim, Lee and Min, 2017). Furthermore, the coastline can also be generated by classifying beach features using remote sensing images, namely by extracting water and non-water pixels, for example from multispectral, radar and hyperspectral images (Al Fugura, Billa and Pradhan, 2011; Dewi, Bijker and Stein, 2017). 
In this study, the second approach was adopted; coastline was extracted from an intersection between a seamless digital elevation and bathymetry model (DEBM) and the water level for i.e., the LAT and HAT as in Oktaviani et al., (2021). After performing gridding method, coastlines were generated by computing the intersection line between the seamless DEBM and water level for i.e., LAT and HAT obtained from the previous step. The concept of coastline developed in this study can be seen in Fig. 3.

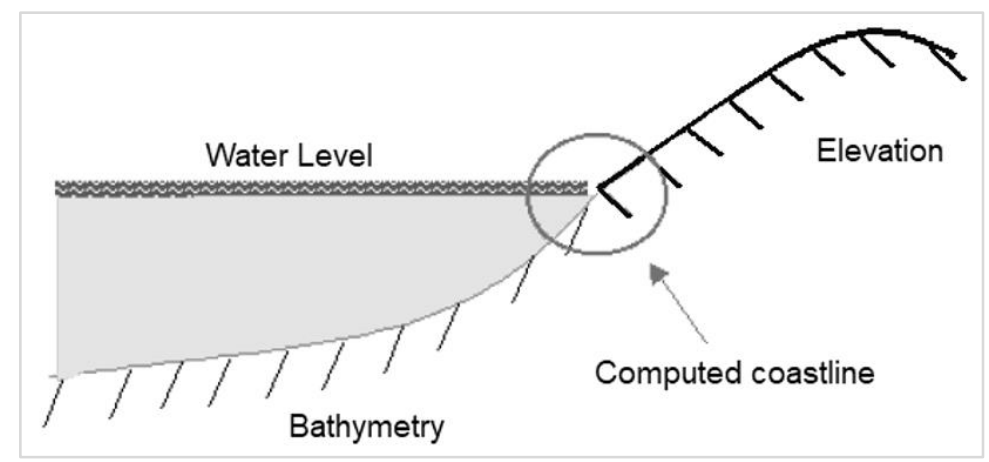

Fig. 2. Coastline estimated from an intersection between seamless digital elevation and bathymetry model and water level (modified from Li, Di and Ma (2004)).

\subsection{Estimating basepoints, baselines and maritime boundaries}

The LAT coastline was used as a reference in determining the basepoint while the HAT coastline was used to identify islands. To determine whether an object is an island, we referred to the definition provided by UNCLOS (United Nations Convention on the Law of the Sea) 1982 convention (United Nation, 1982). The mass of land which is visible during high and low tides is called an island/rock, however, when it is only visible during the low tide, it is called as low tide elevation (LTE). The first term is in line with the definition provided in UNCLOS Article 121 (United Nation, 1982): "An island is a naturally formed area of land, surrounded by water, which is above water at high tide". The second term is described in Article 13: "A low-tide elevation is a naturally formed area of land which is surrounded by and above water at low tide but submerged at high tide". Both concepts are visualized in Fig. 4.

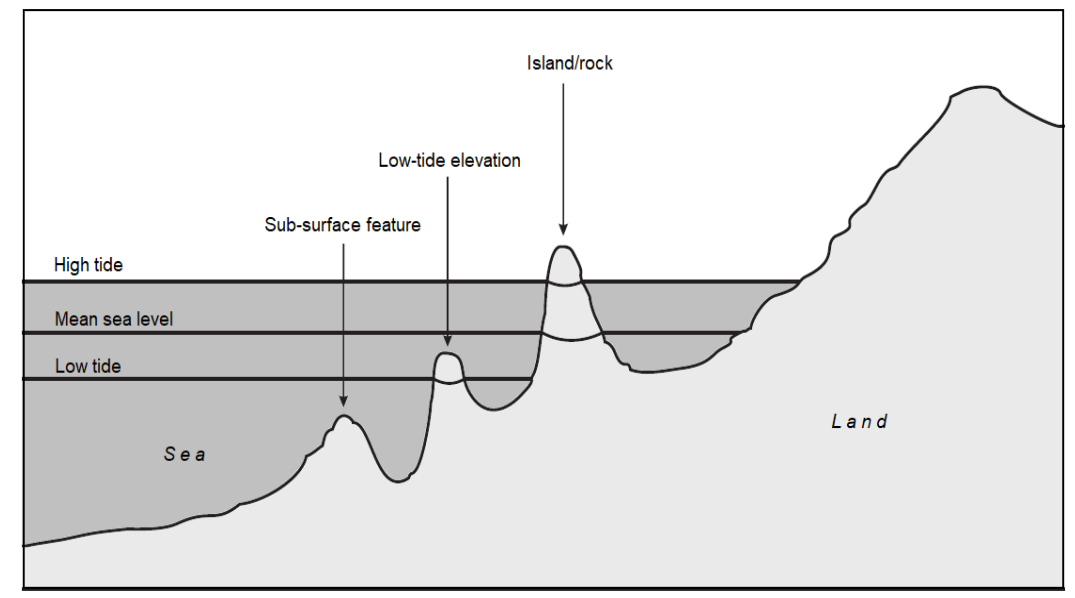

Fig. 3. The concept of island, low-tide elevation and sub-surface feature based on UNCLOS 1982 (modified from Schofield and Arsana (Schofield and Arsana, 2012)). 
For this study, a method from Presscott and Schofield (2005) was adopted to estimate the basepoint location. The presence of any possible outermost island was assessed by using the HAT coastline and the position of the headland were assessed as well. In the next step, two straight lines were drawn on the side of the headlands and the angle formed by the intersection of both straight lines were measured. Furthermore, the measured angle was divided in half to create a bisector of tangents as a line that divides the angle equally. The intersection of this bisector of tangents line with the LAT coastline was then considered as basepoints (see Fig. 5).

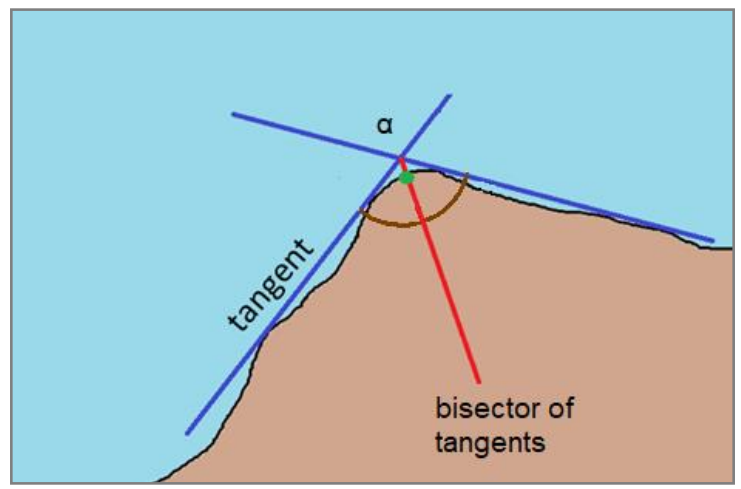

Fig. 4. Locating the basepoint (green dot) at the position of the intersection between bisector of tangents line (red line) with the LAT coastline (modified from Presscott and Schofield (Presscott and Schofield, 2005)).

A baseline was created by joining the proposed basepoint resulted from this study with the available basepoints. For this purpose, given the situation of the study area, we generated a normal baseline and straight lines across the mouth of rivers. UNCLOS (United Nation, 1982) defines the normal baseline to measure the breadth of the territorial sea as the low-water line along the coast officially recognized by the government. Whereas, the closing of river mouth is conducted when a river flows directly into the sea. In this situation, we need to develop a straight line across the mouth of the river between points on the low-water line of its banks (United Nation, 1982). In this research, the position on the low-water line refers to the LAT coastline.

Lastly, the maritime boundary was developed by integrating the proposed baseline from this study with the existing archipelagic baselines from nearby basepoints (TD.161 and TD.162 as in Fig. 1). We compared the results with the existing baselines which was developed by joining the existing basepoints located at the low water line along the coast. They were determined by direct measurement via hydrographic survey at the nearshore area by the Indonesia Government. From the resulted baseline, we generated the boundary of territorial sea, contiguous zone and the exclusive economic zone. In fact, a state can develop four types of zones, namely: territorial sea, contiguous zone, continental shelf, and exclusive economic zone (Specht, 2019).

\section{RESULTS}

\subsection{The result of SDB model and the estimation of LAT and HAT coastlines}

Fig. 6a presents the results of the SDB model while Fig. 6b shows false color composite of Sentinel 2A as visual comparison. The estimated depth in the SDB model were from $>0 \mathrm{~m}$ up to less than $30 \mathrm{~m}$, and the model clearly delineated land area of zero depth around the existing land and shallow water area representing by grey to white pixels in Fig. $\mathbf{6 b}$.

The tidal harmonic constituents' analysis results are plotted in Fig. 7. The plot of tide gauge data is in blue, the predicted tide level is in orange and the residual of sea level is in red lines. The tidal analysis results show that water level observation fit with the predicted water level by using T-Tide model indicated by a small residual ranging from $20-30 \mathrm{~cm}$. 


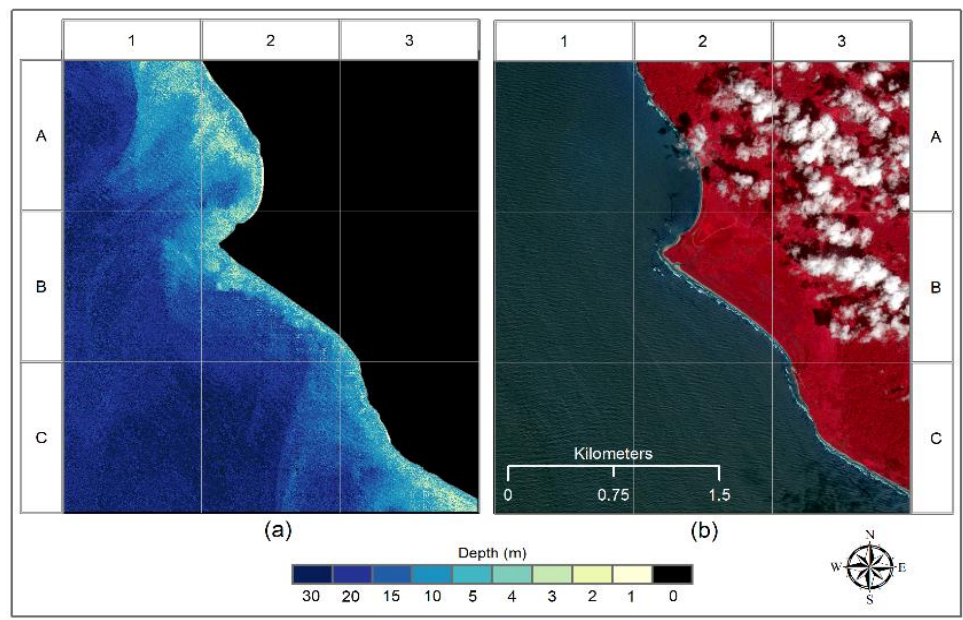

Fig. 5. Visualization of depth produced when performing RF in the study area; and (b) false colour composite of Sentinel 2A image (dark blue pixels are water; red pixels are vegetation and grey to white are very shallow water with submerge rocks).

This residual was classified as meteorological residual which is a non-tidal component resulted by removing regular tides in the analysis (Pugh, 1987). The model produced 71 tidal constituents which were further used to predict the water level in Siberut Island for 19 years. From the result in Fig. 7, the LAT was $26.77 \mathrm{~cm}$ while the HAT was $202.49 \mathrm{~cm}$.

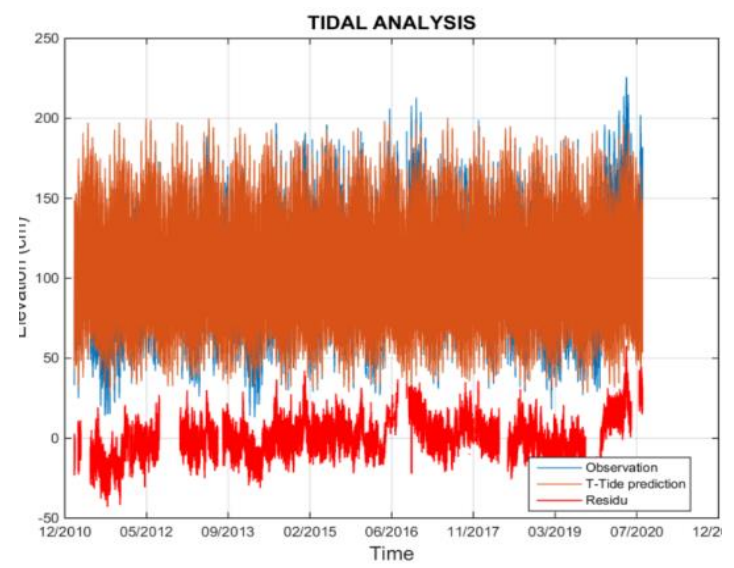

(a)

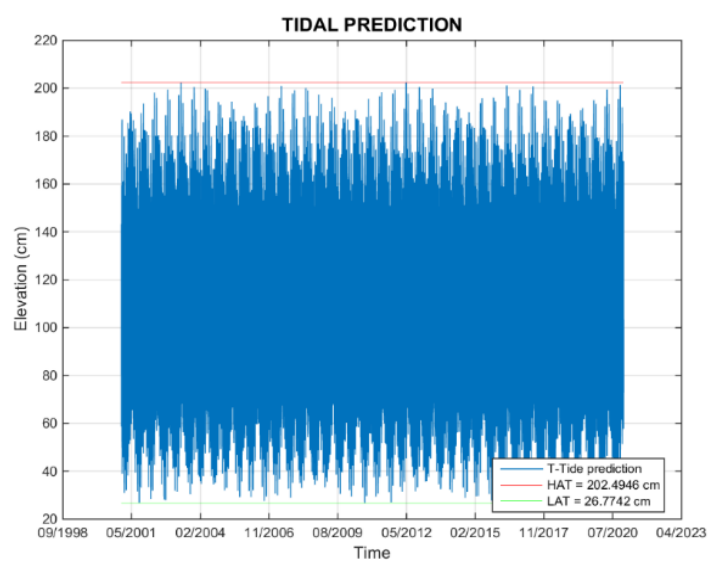

(b)

Fig. 6. (a) Hourly tide gauge data (blue line), the results of T-Tide prediction (orange line) and the residual of sea level (red line) as the results of tidal analysis; (b) Tidal prediction in blue line and the estimates of LAT (green line) and the HAT in red line. The $\mathrm{x}$-axis is the time of measurement and $\mathrm{y}$-axis is the sea level in $\mathrm{cm}$.

\subsection{The result of elevation and bathymetry integration and coastline extraction}

Integration results between elevation and bathymetry data using spline interpolation-based method (gridding method) is presented in Fig. 8a. Whereas, Fig. 8b-c show the visual comparison of the proposed result with other depth data, namely from SDB (Fig. 8b) and the national bathymetry data (Fig. 8c). The SDB model seems a bit noisy while the national bathymetry data has less detailed information. The integration of elevation and all available bathymetry data was successful in deriving quite detail information and less noisy bathymetry data as in Fig. 8a. 


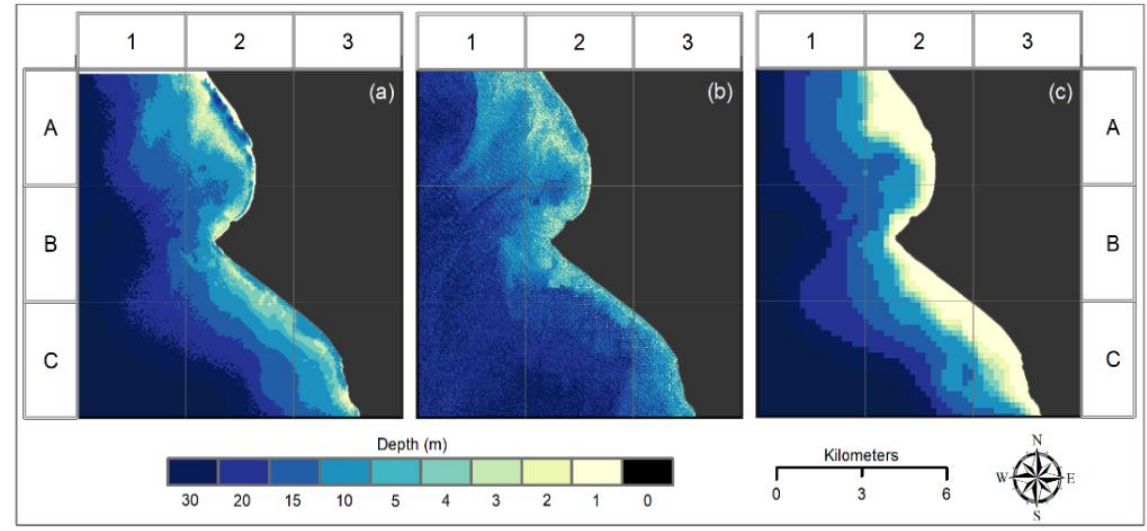

Fig. 7. The visualization of depth data comparison provided by (a) gridding method, (b) SDB model, and (c) the national bathymetry data

In the next step, we derived the LAT and HAT coastlines from the resulted bathymetry data. The results are provided in Fig. 9 showing visual comparisons for coastlines generated by the national bathymetry data (black and magenta lines) and proposed coastlines from gridding method (yellow and tosca lines). From the comparison in Fig. 9, it was obvious that coastlines resulted from the proposed method presented relatively smooth coastlines which were close to the shape of the land features. Whereas, rough coastlines from the national bathymetry data were due to lack of detailed depth information in shallow waters. In this case, we concluded that in locations where depth points maybe less dense, the resulting coastlines would be shifting. Hence, it was critical to have a dense depth point especially in shallow water to obtain an accurate coastline.

\subsection{The proposed basepoints, baselines and maritime boundary}

The LAT and HAT coastlines presented in Fig. 9 were used to update the position of basepoint and baseline in the study area.

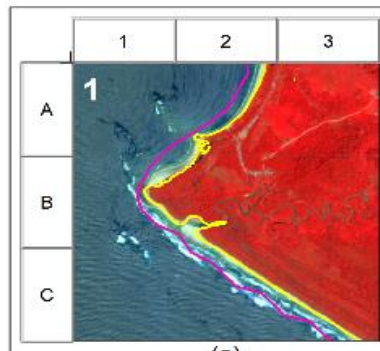

(a)

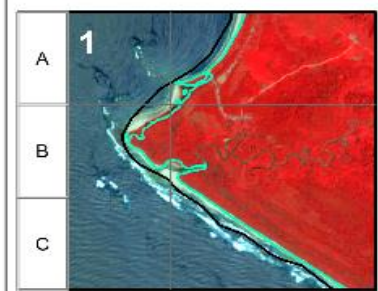

(c)

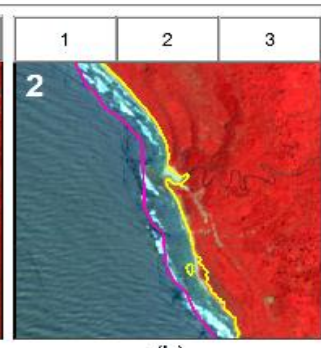

(b)

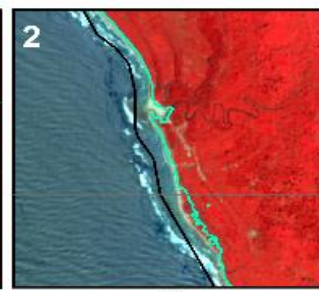

(d)

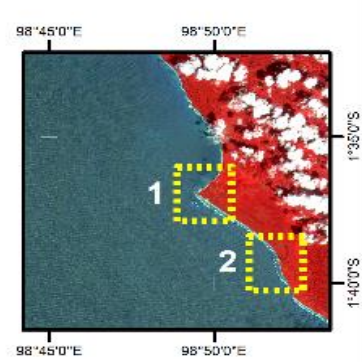

COASTLINES:

Proposed LAT

National Bathymetri LAT

Proposed HAT

- National Bathymetri HAT

Vegetation

QShallow wate
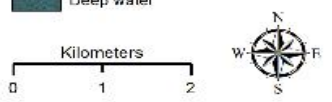

Fig. 8. The visualization of LAT (a-b) and HAT (c-d) coastlines. For each coastline type, comparisons are given for coastlines generated by the national bathymetry data (black and magenta lines), and proposed coastlines from gridding method (yellow and tosca lines). False colour composite of Sentinel 2A is used as the background. 
From visual inspection on the HAT coastline, we confirmed that there was no small island which was identify near the TD.161B. Therefore, we concluded that the baseline was still located at the Siberut Island. Meanwhile, by using the LAT coastline, we assessed the position of the new basepoint located in Cape Simansih approximately $171.58 \mathrm{~m}$ to the north of the existing point i.e. TD.161B (as in Fig. 10b).

After updating the basepoint, we obtained a new normal baseline (see red line in Fig. 10a). From the LAT coastlines, three rivers located nearby TD.161B were closed by straight lines across the mouth of the rivers (see Fig. 10 c-e). In this case, we proposed a new baseline position produced by integrating a normal baseline and straight lines across the mouth of rivers. Fig. 10 a-b show a visual comparison between the existing baseline and the new baseline resulted from the proposed method.

From the results, we can see that the proposed baseline was more accurate indicated by its position that was closely linked to the land. Finally, we updated the archipelagic baseline by connecting the updated TD.161B with the existing TD nearby namely: TD.161 and TD.162. Consequently, we updated new positions of Indonesia maritime boundary consisting of the boundaries of territorial, contiguous, and exclusive economic zones as in Fig. 11a. Fig. 11b-d present visual comparisons between the existing Indonesia maritime boundaries and the updated boundaries.

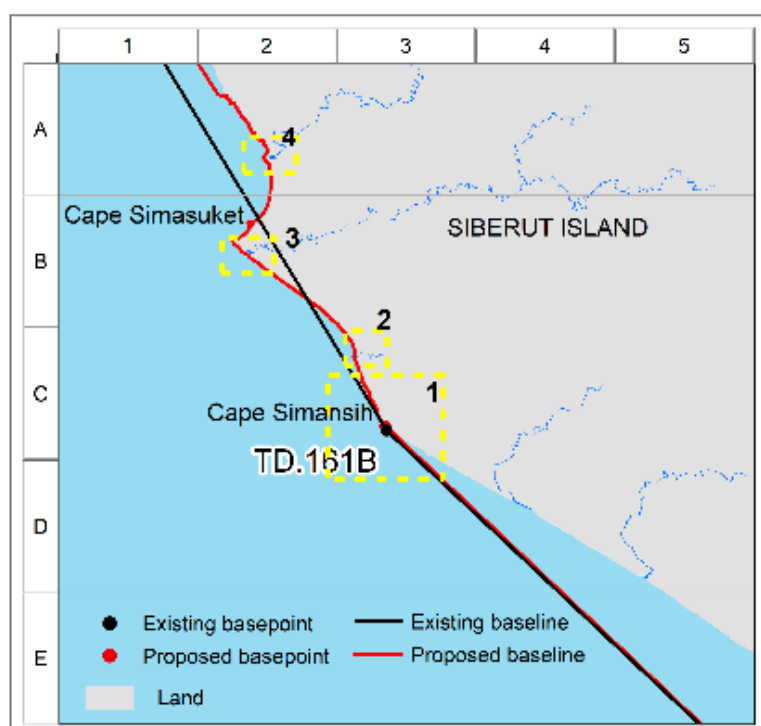

(a)

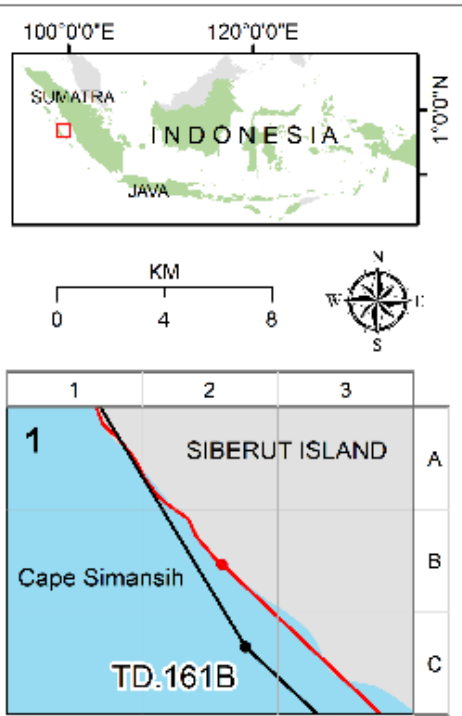

(b)

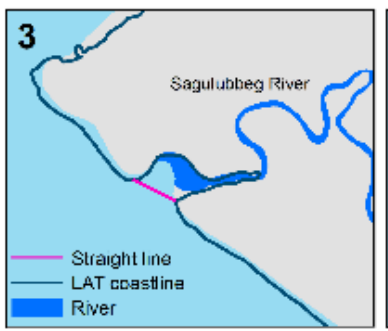

(d)

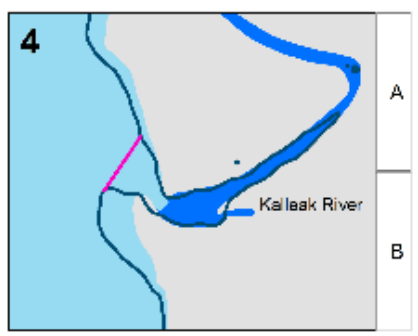

(e)

Fig. 9. (a) The visualization comparison of the existing basepoint TD161B (black dot) and the proposed basepoint (red dot) and zoom in to the location of TD.161B in Cape Simansih. (b) Magenta lines present straight lines develop to close mouth of rivers between points on the low-water line (the LAT coastlines in dark blue lines) of three rivers: (c) Masi River, (d) Sagulubbeg River, and (c) Kalleak River. 


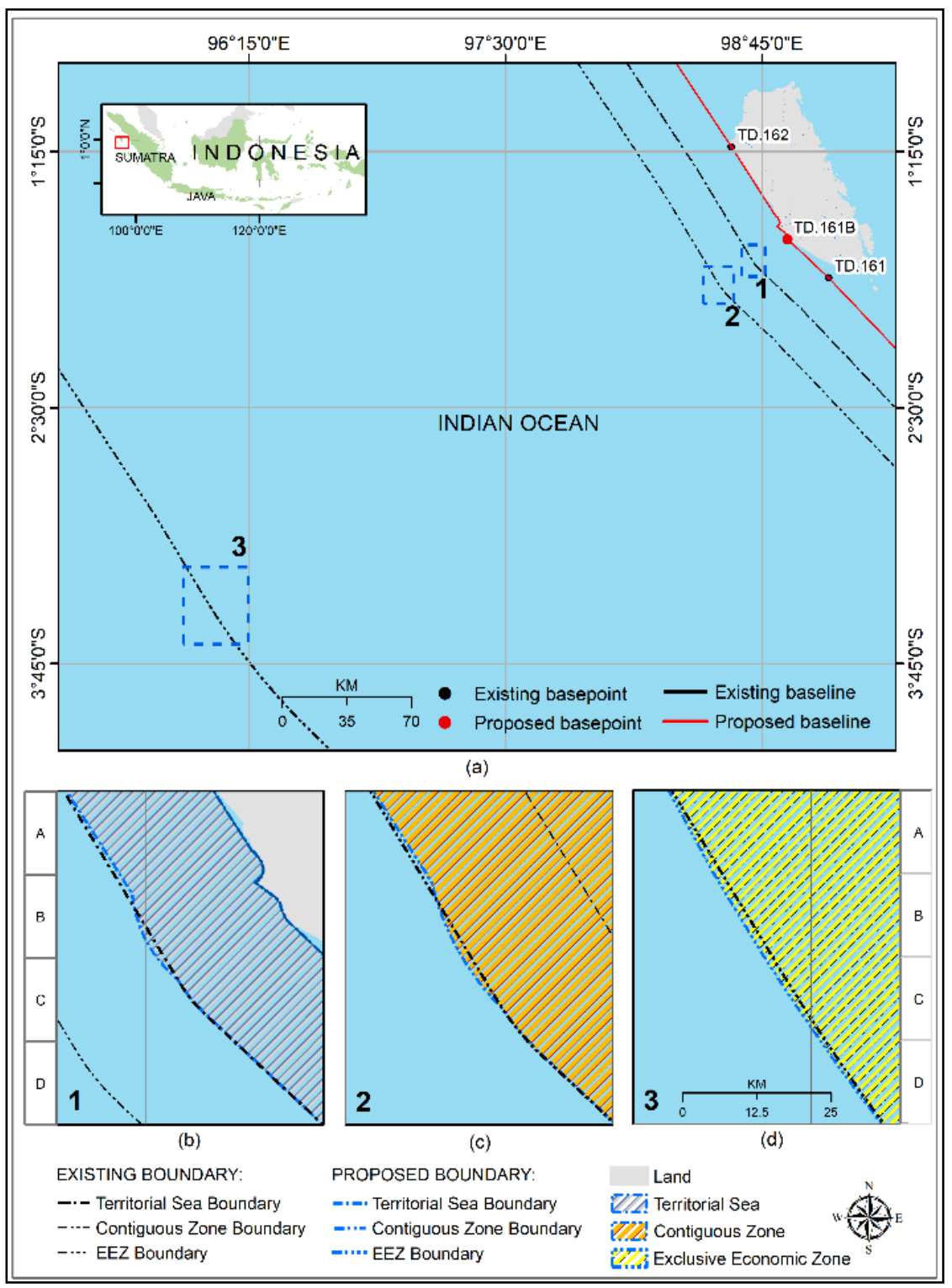

Fig. 10. (a) The visual comparison of the existing Indonesian maritime boundaries and the proposed boundaries and area for (b) territorial sea, (c) contiguous zone, (d) exclusive economic zone.

\section{DISCUSSION}

In this paper, we proposed an alternative method in determining position of basepoints and baselines in order to support the negotiations of Indonesia maritime boundaries. The proposed method was successful in updating the position of a basepoint and baseline in the study area by incorporating and integrating multisource of bathymetry data.

When performing the empirical SDB model to obtain bathymetry data, it was important to have a large amount of training data that represent variability of depth in related location (Geyman and Maloof, 2019; Sagawa et al., 2019). The study area was characterized by high waves and strong winds making it difficult for surveyors to have an access and to conduct echo-sounding measurement. 
Finding other alternatives to obtain training data is an opportunity for future research for example by using unmanned surface vehicles (Suhari et al., 2017). However, high waves and winds at this area may hamper the implementation of such technology.

For this research, tide model was developed by using nine-year observations data producing 71 tidal components and the LAT and HAT were estimated over 19 years period. Parker (2007) stated that an accurate tide prediction is determined by the amplitude and epochs for the tidal components that can be calculated with a given length data time series. It implies that the longer the time series, the closer in frequency two tidal components can be solved for.

The LAT and HAT coastline can be calculated over a minimum period of 19 years using harmonic constants that are derived from the minimum of a one year observation (Ko et al., 2018). However, the longer the observations, the smaller the standard deviation of each component and the better the prediction will be (Bruce B. Parker, 2007; Supriyono et al., 2015).

We integrated bathymetry data by using gridding method. In this case, lower resolution of the national bathymetry data was stacked with a middle resolution of SDB model and a higher resolution of echo-sounding measurement points. The challenging part was in carrying out the stacking process involving various resolutions and in the same time suppressing gridding artifacts. Spline interpolation approach by adjusting an individual tension for each grid resolution was successful in maintaining small details in the bathymetry data and suppressing the artefacts caused by higher resolution data (Hell and Jakobsson, 2011). However, it required higher computational requirements.

The determination of basepoint and baseline positions was influenced by the presence of land features that may be identified during coastline extractions specifically when deriving the HAT coastline. In this case, the UNCLOS (United Nation, 1982) defined island as the naturally formed area of land which is above water during the high tide. Hence, it is important to define such features when generating the coastline since the presence of the island would determine how the basepoint and baseline would be developed.

\section{CONCLUSIONS}

This study presents an alternative method to determine the position of basepoints and baselines of the Indonesia maritime boundary which can also be applied to any other archipelagic countries. The use of remote sensing data and techniques was successful to overcome the problem of data limitation in the study area, especially ground survey data. In addition, the proposed method could be used to detect low tide elevation (LTE). In fact, an archipelagic countries are not able to use LTE as a basepoint, unless there is a permanent building on that certain location. However, the detected LTE information can be used to assist the planning of permanent buildings in the area.

Some challenges for the improvement of the method includes: a) to search for other alternative in obtaining training data when applying SDB model; and b) multitemporal observation maybe needed since the positions of these basepoint and baseline may vary in time. The method proposed in this study can be easily be adopted to any other locations. However, the procedures would be determined by the availability of data in the related locations.

The proposed basepoint obtained from this research is expected to be used as an input to update the existing basepoint. Furthermore, the proposed method from this research is also expected to be used as a basis to refine the whole existing baselines in Indonesia (as in Government Regulation ref. no. 38 of 2002 (Indonesian Government., 2002) and Government Regulation ref. no. 37 of 2008 (Indonesian Government., 2008)) so that an optimal configuration of the maritime boundaries can be obtained. Changes in the position of basepoints and baselines would certainly not change the previously agreed maritime boundary agreement as has been mentioned in the Vienna Convention Article 62 regarding Fundamental change of circumstances (United Nations, 1969) and the UNCLOS Article 51 (United Nation, 1982): “...an archipelagic State shall respect existing agreements with other States". Finally, in delimiting maritime boundaries with neighbouring countries, accurate basepoints and baselines are decisive factors to obtain an optimum maritime zone which provide a proportionate and equitable solution to both parties. 


\section{ACKNOWLEDGMENTS}

We would like to thank our colleagues from the Center for Marine and Coastal Environment Mapping and the Center for Geodesy and Geodynamic Control Network of the Indonesia Geospatial Information Agency for providing data, related documents, insight and expert inputs that greatly assisted this research.

\section{R E F E R E N C E S}

Arsana, I. M. A., Rizos, C. and Schofield, C. (2006) 'The Application of GIS in Maritime Boundary Delimitation A case study on the Indonesia-East Timor Maritime Boundary', in Abdul-Rahman, A., Zlatanova, S., and Coors, V. (eds) Innovations in 3D Geo Information Systems. Springer, Berlin, Heidelberg, pp. 695-719. doi: 10.1007/978-3-540-36998-1.

Becker, J. J. et al. (2009) 'Global Bathymetry and Elevation Data at 30 Arc Seconds Resolution: SRTM30_PLUS’, Marine Geodesy, 32(4), pp. 355-371. doi: 10.1080/01490410903297766.

Boak, E. H. and Turner, I. L. (2005) 'Shoreline Definition and Detection: A Review', Journal of Coastal Research, 214(1), pp. 688-703. doi: 10.2112/03-0071.1.

Breiman, L. (2001) 'Random Forests', Machine Learning, 45(1), pp. 5-32. doi: 10.1023/A:1010933404324.

Bruce B. Parker, P. D. (2007) Tidal Analysis and Prediction, Sea-Level Science. NOAA Special Publication NOS CO-OPS 3. doi: 10.1017/cbo9781139235778.007.

Dewi, A., Sugianto, D. N. and Diponegoro, U. (2018) 'Analysis of Wave Deformation on Siberut Island, Mentawai Islands Regency, West Sumatra', Journal of Oceanography, 6(2), pp. 330-340.

Dewi, R. S. et al. (2018) 'Transferability and upscaling of fuzzy classification for shoreline change over 30 years’, Remote Sensing, 10(9). doi: 10.3390/rs10091377.

Dewi, R. S., Bijker, W. and Stein, A. (2017) 'Comparing fuzzy sets and random sets to model the uncertainty of fuzzy shorelines', Remote Sensing. doi: 10.3390/rs9090885.

ESA (2015) 'SENTINEL-2 User Handbook', Sentinel-2 User Handbook.

ESA (2020) Copernicus Open Access Hub. Available at: https://scihub.copernicus.eu/dhus/\#/home.

FIG Commission 4 and 5. (2006) FIG Guide on the Development of a Vertical Reference Surface for Hydrography, International Federation of Surveyors Publication. Copenhagen. Available at: http://www.fig.net/pub/figpub/pub37/pub37.pdf.

Ford, M. (2013) 'Shoreline changes interpreted from multi-temporal aerial photographs and high resolution satellite images: Wotje Atoll, Marshall Islands', Remote Sensing of Environment. doi: 10.1016/j.rse.2013.03.027.

Al Fugura, A., Billa, L. and Pradhan, B. (2011) 'Semi-automated procedures for shoreline extraction using single RADARSAT-1 SAR image', Estuarine, Coastal and Shelf Science. doi: 10.1016/j.ecss.2011.10.009.

Geospatial Information Agency. (2011) Geospatial Information Law 04/2011. Indonesia.

Geospatial Information Agency. (2018a) Daftar Stasiun (Tide Gauge Station). Available at: http://inasealevelmonitoring.big.go.id/ipasut/data/station (Accessed: 1 February 2020).

Geospatial Information Agency. (2018b) DEMNAS: Seamless Digital Elevation Model (DEM) dan Batimetri Nasional. Available at: https://tanahair.indonesia.go.id/demnas/\#/.

Geyman, E. C. and Maloof, A. C. (2019) 'A Simple Method for Extracting Water Depth From Multispectral Satellite Imagery in Regions of Variable Bottom Type', Earth and Space Science. doi: 10.1029/2018EA000539.

H2O (2021) Cross Validation. Available at: https://docs.h2o.ai/h2o/latest-stable/h2o-docs/cross-validation.html (Accessed: 2 June 2021).

Hell, B. and Jakobsson, M. (2011) 'Gridding heterogeneous bathymetric data sets with stacked continuous curvature splines in tension', Marine Geophysical Research, 32(4), pp. 493-501. doi: 10.1007/s11001-011$9141-1$. 
IHO. (2008) 'IHO Standards for Hydrographic Surveys (S-44) 5th Edition'.

Indonesian Government. (2002) Government Regulation 38/2002: List of Geographical Coordinates of the Points of the Base Line of the Indonesian Archipelago. Indonesia.

Indonesian Government. (2008) Government Regulation 37/2008: Amendment to Government Regulation Number 38 of 2002 Concerning List of Geographic Coordinates of the Points of the Baseline Line of Indonesian Islands. Indonesia.

Julzarika, A. et al. (2021) 'Integration of the Latest Digital Terrain Model (DTM) with Synthetic Aperture Radar (SAR) Bathymetry', J. Degrade. Min. Land Manage, 8(3), pp. 2759-2777. doi: 10.15243/jdmlm.

Karim, S. (2011) 'Geography of West Sumatra and Earthquake Natural Disaster'. Jurusan GeograJi Fakultas Ilmu Sosial Universitas Negeri Padang. Available at: http://repository.unp.ac.id/17760/1/SUTARMAN KARIM_68_11.pdf.

Kim, H., Lee, S. B. and Min, K. S. (2017) 'Shoreline change analysis using airborne LiDAR bathymetry for coastal monitoring BT - 2nd International Water Safety Symposium, IWSS 2016, June 22, 2016 - June 24, 2016', 33(Special Issue 79), pp. 269-273. doi: 10.2112/SI79-055.1.

Ko, D. H. et al. (2018) 'Analysis on the estimation errors of the lowest and highest astronomical tides for the southwestern 2.5 GW offshore wind farm, Korea', International Journal of Naval Architecture and Ocean Engineering, 10(1), pp. 85-94. doi: 10.1016/j.ijnaoe.2017.03.004.

Li, R., Di, K. and Ma, R. (2004) 'A comparative study of shoreline mapping techniques', in GIS for Coastal Zone Management. doi: 10.1201/9781420023428.ch3.

Liu, H. (2008) 'Shoreline Mapping and Coastal Change Studies Using Remote Sensing Imagery and LIDAR Data', in Remote Sensing and Geospatial Technologies for Coastal Ecosystem Assessment and Management. doi: 10.1007/978-3-540-88183-4_13.

Manessa, M. D. M. et al. (2016) 'Satellite-Derived Bathymetry using Random Forest Algorithm and Worldview2 Imagery', Geoplanning: Journal of Geomatics and Planning; Vol 3, No 2 (2016): (October 2016)DO 10.14710/geoplanning.3.2.117-126.

Available

at: https://ejournal.undip.ac.id/index.php/geoplanning/article/view/12047.

Mustafa, B. (2010) 'Analysis of the Nias earthquake and the West Sumatra earthquake and their similarities that do not cause a tsunami', JURNAL ILMU FISIKA, 2(1), pp. 44-50.

NOAA (2021) Mapping and Charting. Available at: https://tidesandcurrents.noaa.gov/mapping.html (Accessed: 28 February 2021).

Oktaviani, N. et al. (2021) 'Pemodelan Garis Pantai Menggunakan Metode Interpolasi Stacked Curve Spline Pemodelan Garis Pantai Menggunakan Metode Interpolasi Stacked Curve Spline Tension', (August). doi: 10.14710/teknik.

Pawlowicz, R., Beardsley, B. and Lentz, S. (2002) 'Classical tidal harmonic analysis including error estimates in MATLAB using TDE', Computers and Geosciences, 28(8), pp. 929-937. doi: 10.1016/S00983004(02)00013-4.

PCTMSL (2014) Australian Tides Manual Special Publication No. 9.

Presscott, V. and Schofield, C. (2005) The Maritime Political Boundary of the World. Second Edi. Boston: Martinus Nijhoff Publishers.

Pugh, D. T. (1987) Tides, Surges and Mean Sea-Level. Chichester, UK: John Wiley \& Sons.

Sagawa, T. et al. (2019) 'Satellite derived bathymetry using machine learning and multi-temporal satellite images', Remote Sensing. doi: 10.3390/rs11101155.

Schofield, C. and Arsana, A. (2012) 'Climate change and the limits of maritime jurisdiction', in Warner, R. and Schofield, C. (eds) Climate Change and the Oceans. Massachusetts: Edward Elgar Publishing Limited, pp. $127-152$.

Siddig, N. A., Al-subhi, A. M. and Alsaafani, M. A. (2019) 'Tide and mean sea level trend in the west coast of the Arabian Gulf from tide gauges and multi-missions satellite altimeter', Oceanologia, 61(4), pp. 401411. doi: 10.1016/j.oceano.2019.05.003. 
Sinclair, M. J., Stephenson, D. J. and Barker, R. M. (2003) 'Alaska Peninsula deployment of laser airborne bathymetric system', Oceans Conference Record (IEEE), 2, pp. 770-779. doi: 10.1109/oceans.2003.178412.

Specht, C. et al. (2017) 'Determination of the Territorial Sea Baseline - Measurement Aspect', IOP Conference Series: Earth and Environmental Science, 95(3). doi: 10.1088/1755-1315/95/3/032011.

Specht, M., Specht, C., Waz, M., Dabrowski, P., et al. (2019) 'Determining the variability of the territorial sea baseline on the example of waterbody adjacent to the municipal Beach in Gdynia', Applied Sciences (Switzerland), 9(18). doi: 10.3390/app9183867.

Specht, M., Specht, C., Waz, M., Naus, K., et al. (2019) 'Methodology for performing territorial sea baseline measurements in selected waterbodies of Poland', Applied Sciences (Switzerland), 9(15). doi: 10.3390/app9153053.

Suhari, K. T. et al. (2017) 'Small ROV Marine Boat for Bathymetry Surveys of Shallow Waters - Potential Implementation in Malaysia', in The International Archives of the Photogrammetry, Remote Sensing and Spatial Information Sciences, pp. 201-208. doi: 10.5194/isprs-archives-XLII-4-W5-201-2017.

Suparno. (2006) 'Surfing Tourism as the Prima Dona of Marine Environmental Services in the Mentawai Islands Regency, West Sumatra', Jurnal Mangrove dan Pesisir, VI(3), pp. 32-39.

Supriyono et al. (2015) 'Tide Prediction Analysis and Calculation using Admiralty Method and Least Square Method (Case Study of Tarakan and Balikpapan Waters)', Chart Datum, 01 No.01, pp. 8-18.

Thiébot, J., Guillou, S. and Droniou, E. (2020) 'Influence of the 18.6-year lunar nodal cycle on the tidal resource of the Alderney Race, France', Applied Ocean Research, 97(102107). doi: 10.1016/j.apor.2020.102107.

United Nation (1982) UNCLOS 1982, United Nation. doi: 10.1080/00908329509546068.

United Nations (1969) Vienna Convention on the law of treaties, Treaty Series. United Nations. doi: $10.4337 / 9781781006047.00014$. 